\title{
Simultaneous Speciation of Iron(II) and Iron(III) by Ion Chromatography with Chemiluminescence Detection
}

\author{
Yun-Chieh ChEN,* Yu-Ling JiAn,* Kong-Hwa ChIU,** and Hwa-Kwang YAK*广 \\ *Green Chemistry Lab, Department of Chemistry, Chung Yuan Christian University, 200, Jhong Bei Road, \\ Chung-Li 32023, Taiwan, R. O. C. \\ **Department of Applied Science, National Dong-Hwa University, Hualien 97064, Taiwan, R. O. C.
}

\begin{abstract}
This study reports on a method for the speciation of iron in aqueous samples by the simultaneous analysis of divalent and trivalent iron ions with ion chromatography equipped with chemiluminescence detection (IC-CLD). Ferrous and ferric ions are first chelated by pyridine-2,6-dicarboxylic acid (PDCA) to form complexed anions, and separated by a mixed-bed ion-exchange column. The separated complexed ions are then detected with a CLD system containing luminol and hydrogen peroxide in a basic solution. This luminescence system has a linear dynamic range of $c a$. 3 orders of magnitude, with method detection limits as low as $7 \mu \mathrm{g} \mathrm{L}^{-1}$ for Fe(II) and $3 \mu \mathrm{g} \mathrm{L}^{-1}$ for $\mathrm{Fe}$ (III), measured in the simultaneous detection mode. This system resists interferences from common cations such as $\mathrm{Cd}, \mathrm{Ca}, \mathrm{Cr}, \mathrm{Cu}, \mathrm{Mg}, \mathrm{Ni}, \mathrm{Pb}$, and $\mathrm{Zn}$. Evaluation by analyzing real samples shows that this method is rapid, accurate, sensitive, and selective.
\end{abstract}

(Received March 8, 2012; Accepted July 2, 2012; Published August 10, 2012)

\section{Introduction}

Iron is an important element in the environment, and is widely distributed in nature. It is the fourth most abundant element in the earth's crust, ${ }^{1}$ and has essential roles in biological systems as a trace element. Iron is necessary for hemoglobin synthesis and oxidative processes of living tissues. ${ }^{2,3}$ Both its deficiency and overload can induce various diseases. It has been reported that iron metabolism disorders can cause anemia as well as kidney failures and liver damage (hemochromatosis), which may finally cause arthritis, diabetes, heart failure, liver cirrhosis, or liver cancer. ${ }^{4,5}$

Understanding the state of an element in environmental compartments is important for assessing its biological activity (bioaccumulation, bioconcentration, bioavailability, and toxicity). ${ }^{6}$ In natural water, iron exists in both bivalent and trivalent states, depending on the availability of oxygen. Changes between these two forms of iron are important in various biological and geochemical processes. ${ }^{7}$ The accelerated pace of development, rapid industrialization, and higher population density in modern days have increased the demand for iron substantially, thus resulting in iron pollution, particularly in natural water, to exacerbate over the years. The pollution of iron arises mainly from mineral separation, smelting, etch cleaning, and electroplating. Therefore, measuring the form of the iron content is very important for evaluating the quality of natural water.

Most of the present instrumental methods for the determination of iron, such as UV-visible spectrophotometry, colorimetry, atomic absorption spectrometry (AAS), atomic emission spectrometry (AES), and inductively-coupled plasma (ICP)

$\dagger$ To whom correspondence should be addressed.

E-mail: hkyak@cycu.edu.tw methods cannot perform speciation directly. Recently, ICP methods, especially those coupled with mass spectrometry detection (ICP-MSD), have been used vastly with ion-chromatography (IC) for the simultaneous speciation of many elements, including iron, with very low detection limits. ${ }^{8}$ Despite all of the advantages that ICP-MSD offers, this technique is prohibitively expensive to purchase and maintain, and the analysis cost per sample is typically high. On the other hand, chemiluminescence (CL) detection enables rapid, simple, and economical detection of many elements and substances..$^{9-12}$ The most studied CL system is the luminol (5-amino-2,3dihydro-1,4-phthalazinedione) reaction, which undergoes oxidative reaction by oxidants, such as dissolved oxygen, hydrogen peroxide and potassium periodate and produces photons in the blue light region. ${ }^{13}$ This method is widely used as an analytical tool for many applications, such as analyses of a variety of trace metals and other substances. ${ }^{7,14-17}$

Numerous analytical techniques have been employed in the determination of heavy and transition metals, but ion chromatography seems to be one of the most effective and simple techniques to determine both anionic and cationic species, owing to its high separation efficiency and selectivity, and probable simultaneous determination of different oxidation states of the same element via flow injection analysis (FIA). The eluent commonly used for this application is oxalic acid or pyridine-2,6-dicarboxylic acid (PDCA). ${ }^{18,19}$ Nonetheless, few studies on the simultaneous determination of iron(II) and iron(III) have been reported to date using this technique. ${ }^{19-21}$ All of these reports involve the use of a metal complexing agent, such as 4-(2-pyridylazo)resorcinol (PAR) or 2-(5-bromo-2pyridylazo)-5-diethylaminophenol (5-Br-PADAP) added postcolumn to form a light-absorbing complex with transition metals, which are then detectable by a UV-VIS detector at $530 \mathrm{~nm}$. Cardellicchio et al. reported detection limits of 2.2 and $0.3 \mu \mathrm{g} \mathrm{L}^{-1}$ for $\mathrm{Fe}(\mathrm{II})$ and $\mathrm{Fe}(\mathrm{III})$, respectively, with a $750-\mu \mathrm{L}$ 
injection volume. ${ }^{20}$ The goal of this research is to develop a rapid, sensitive, selective, simple, and economical analytical method for the simultaneous speciation of iron species based on the same IC system described above, but equipped with luminol chemiluminescence detection.

\section{Experimental}

\section{Reagents}

Luminol (97\%) was purchased from Sigma-Aldrich (Steinheim, Germany). A 30\% (w/w) $\mathrm{H}_{2} \mathrm{O}_{2}$ solution, $\mathrm{KCl}$, and $\mathrm{Na}_{2} \mathrm{CO}_{3}$ were purchased from Showa (Tokyo, Japan). $\mathrm{HCOOH}$ was purchased from Acros (NJ). $\mathrm{KOH}$, pyridine-2,6-dicarboxylic acid (PDCA), $\mathrm{FeSO}_{4} \cdot 7 \mathrm{H}_{2} \mathrm{O}$ crystals, and $\mathrm{Fe}(\mathrm{III})$ standard solution (1000 $\mathrm{mg} \mathrm{L}^{-1}$ ) were purchased from Merck (Darmstadt, Germany). An Fe(II) stock solution (about $1000 \mathrm{mg} \mathrm{L}^{-1}$ ) was prepared by dissolving $\mathrm{FeSO}_{4} \cdot 7 \mathrm{H}_{2} \mathrm{O}$ in $0.1 \mathrm{M} \mathrm{HCl}$ in the lab. Working standard solutions were prepared fresh daily by a stepwise dilution of the stock solution with deionized water produced from a Milli-Q purification system. Figure 1 shows the structure of PDCA, while Fig. 2 illustrates the chemiluminescent mechanism of luminol. ${ }^{22}$

\section{Apparatus}

A flow system illustrated in Fig. 3 consists of an IC pump (Methrohm 709) and a peristaltic pump (Dynamax RP-1), a CL detector (Soma Optics, Model S-3400) and a 100- $\mu$ L loop valve injector placed before the IC column. The IC column consists of a Dionex IonPac CS5A $(4 \times 50 \mathrm{~mm})$ guard column and a Dionex IonPac CG5A $(4 \times 250 \mathrm{~mm})$ mixed-bed column. This mixed-bed column contains both anionic and cationic exchange sites, and has a speciation capability on many transitional metals, including iron, ${ }^{19}$ and is commonly used as an ion-exchange column for such studies. The eluent is a solution of pyridine-2,6-dicarboxylic acid (PDCA), $\mathrm{KOH}, \mathrm{HCOOH}$, and $\mathrm{KCl}$ adjusted to $\mathrm{pH} 4$ with $\mathrm{KOH}$. The luminol is contained in the postcolumn reagent, which includes $\mathrm{Na}_{2} \mathrm{CO}_{3}$ and luminol adjusted to $\mathrm{pH} 11.5$ with $\mathrm{NaOH}$. This luminol solution and a $\mathrm{H}_{2} \mathrm{O}_{2}$ solution were delivered by a 2-channel peristaltic pump and mixed prior to joining the flow from the main column. The flow-rate of the eluent is $1.2 \mathrm{~mL} \mathrm{~min}^{-1}$, while the postcolumn reagent is added at $0.25 \mathrm{~mL} \mathrm{~min}^{-1}$.<smiles>O=C(O)c1cccc(C(=O)O)n1</smiles>

$$
\mathrm{pK} \mathrm{a}_{1}=2.16
$$

$\mathrm{pKa} \mathrm{a}_{2}=6.92$

Fig. 1 Structure of pyridine-2,6-dicarboxylic acid.

\section{Results and Discussion}

\section{Optimizing the eluent conditions}

Effect of complexing reagent. Pyridine 2,6-dicarboxylic acid (PDCA) is an ionizable compound $\left(\mathrm{p} K_{\mathrm{a} 1}=2.16 ; \mathrm{p} K_{\mathrm{a} 2}=6.92\right)$. It is commonly used as a chelator for metal-PDCA complexes for the separation of heavy and transition metals. ${ }^{23-25}$ Under suitable conditions, divalent and trivalent metals form anionic complexes with PDCA as $\mathrm{M}^{\mathrm{n}+}(\mathrm{PDCA})_{2}{ }^{\mathrm{n}-4}$. In this study, $\mathrm{Fe}(\mathrm{II})$ and $\mathrm{Fe}(\mathrm{III})$ form complexes with PDCA as Fe[PDCA $]_{2}{ }^{2-}$ and $\mathrm{Fe}[\mathrm{PDCA}]_{2}{ }^{-}$, with $\log K_{\mathrm{f}}=10.36$ and 17.13 , respectively. ${ }^{26}$ Figure 4 shows the effect of the PDCA concentration and the eluent $\mathrm{pH}$ on the luminosity, while the other parameters are kept constant (eluent: $33 \mathrm{mM} \mathrm{KOH}, 37 \mathrm{mM} \mathrm{HCOOH}$, and $80 \mathrm{mM}$ $\mathrm{KCl}$; postcolumn reagent: $100 \mathrm{mM} \mathrm{Na}_{2} \mathrm{CO}_{3}$ and $0.05 \mathrm{mM}$ luminol adjusted to $\mathrm{pH} 11.5$ with $\mathrm{NaOH}$, and $600 \mathrm{mM} \mathrm{H}_{2} \mathrm{O}_{2}$ ). Figure $4 \mathrm{a}$ shows the effect of the PDCA concentration on the intensity of luminol luminescence. In the beginning, no signal could be detected without the presence of the PDCA. The peak area increases as the PDCA concentration is increased, and reaches a maximum when the PDCA concentration is $8 \mathrm{mM}$, after which the peak area decreases fairly rapidly. This phenomenon is counter intuitive, and suggests that the metal-PDCA complexes may be becoming unstable, likely due to a decrease in the eluent $\mathrm{pH}$ as the PDCA concentration is increased. For verification, the PDCA concentration was fixed at $8 \mathrm{mM}$, while the $\mathrm{pH}$ of the eluent was varied by adding protons. The result shown in Fig. $4 \mathrm{~b}$ confirms that the intensity of luminescence is highly dependent on the eluent $\mathrm{pH}$, and that the optimum $\mathrm{pH}$ value is 4 . By fixing the eluent $\mathrm{pH}$ at 4 , the luminescence indeed becomes proportional to the PDCA concentration (Fig. 4c), and saturates the detector when the PDCA concentration exceeds $10 \mathrm{mM}$. Hence, $10 \mathrm{mM}$ PDCA at $\mathrm{pH} 4$ has been chosen as the optimized condition.

Effect of the presence of a soluble salt in the eluent. Soluble

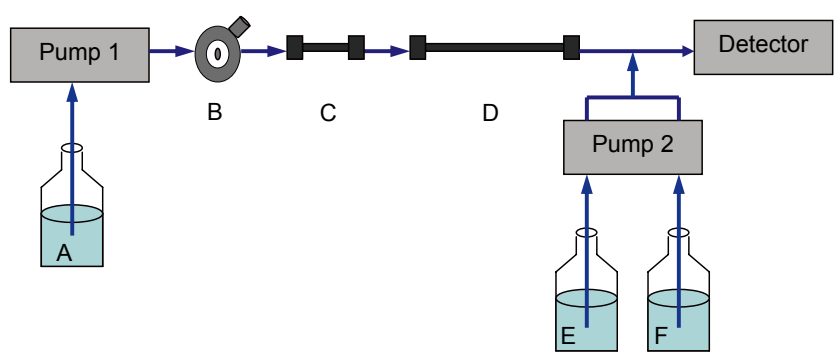

Fig. 3 Schematic diagram of IC-CLD system. A, Eluent; B, injector; C, guard column; D, main column; E, postcolumn reagent (luminol); F, postcolumn reagent (hydrogen peroxide); Pump 1, IC pump; Pump 2, 2-channel peristaltic pump; Detector, chemiluminescence detector.<smiles>Cc1cc(N)c(C(=O)[O-])cc1C(=O)[O-]</smiles>

Fig. 2 Chemiluminescence mechanism of luminol. 

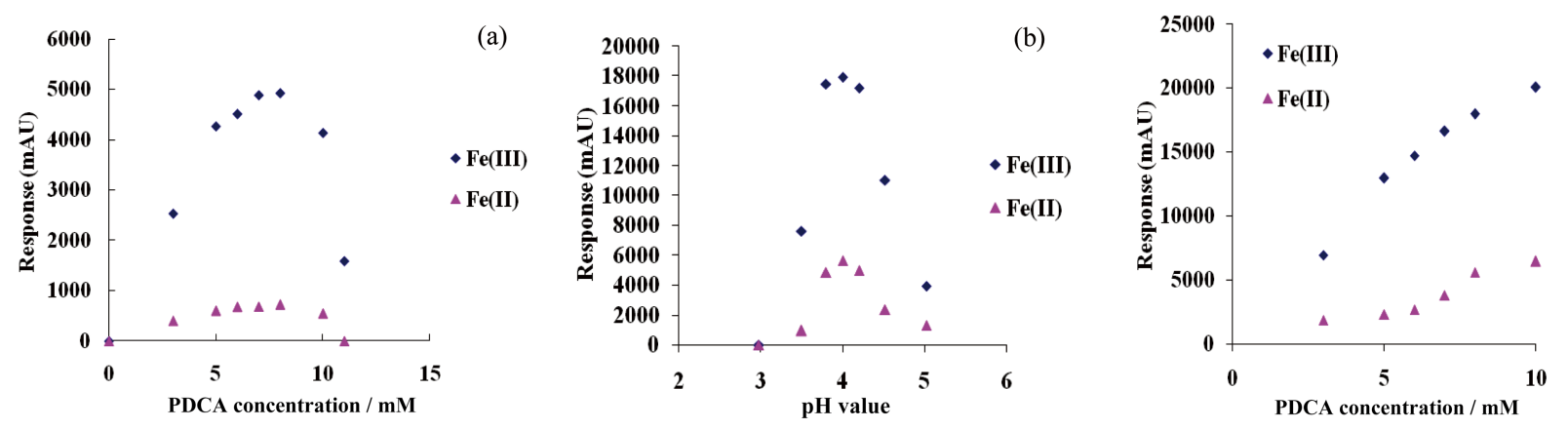

(c)

Fig. 4 (a) Effect of the PDCA concentration, (b) effect of $\mathrm{pH}$ value of the eluent on signal intensity, and (c) effect of PDCA concentration fixed at $\mathrm{pH} 4$ with $\mathrm{HCl}$. The eluent contained $33 \mathrm{mM} \mathrm{KOH}$, $37 \mathrm{mM} \mathrm{HCOOH}$, and $80 \mathrm{mM} \mathrm{KCl}$, and the postcolumn reagent contains $100 \mathrm{mM} \mathrm{Na}_{2} \mathrm{CO}_{3}$ and $0.05 \mathrm{mM}$ luminol adjusted to $\mathrm{pH} 11.5$ with $\mathrm{NaOH}$, and $600 \mathrm{mM} \mathrm{H}_{2} \mathrm{O}_{2}$.

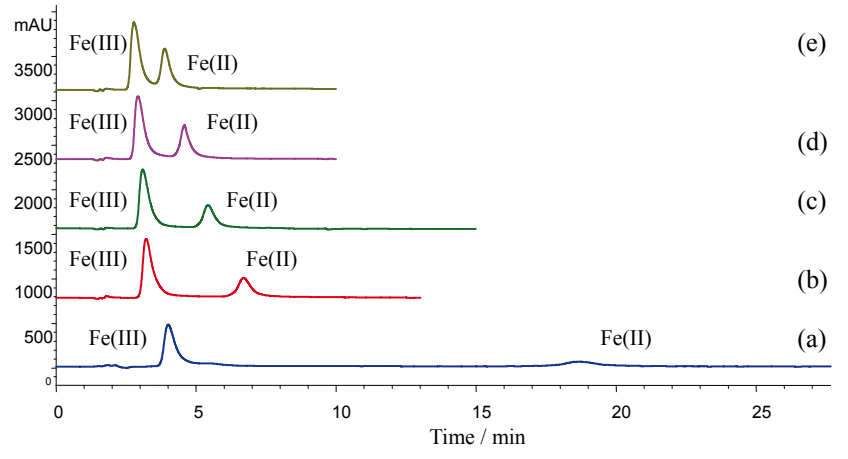

Fig. 5 Effect of the $\mathrm{KCl}$ concentration: (a) 0, (b) 60, (c) 80, (d) 100, (e) $120 \mathrm{mM}$ on migration time and peak width of ferrous and ferric ions. The eluent contained $10 \mathrm{mM}$ PDCA, $33 \mathrm{mM} \mathrm{KOH}$, and $37 \mathrm{mM}$ $\mathrm{HCOOH}$ adjusted to $\mathrm{pH} 4$, and the postcolumn reagent contained $100 \mathrm{mM} \mathrm{Na} \mathrm{CO}_{3}$ and $0.05 \mathrm{mM}$ luminol adjusted to $\mathrm{pH} 11.5$ with $\mathrm{NaOH}$, and $600 \mathrm{mM} \mathrm{H}_{2} \mathrm{O}_{2}$.

salts are added to the eluent to influence the migration of analytes on the column. At the same time, it is also well known that the presence of some halides enhances the intensity of the luminol luminescence. ${ }^{27,28}$ Consequently, adding metal halides may yield multiple benefits to the luminescence analysis. Chloride is by far the most commonly studied, and the salt of choice is $\mathrm{KCl}$. Figure 5 shows the results of the addition of various concentration of $\mathrm{KCl}$ into the eluent, while the other parameters are kept constant (eluent: $10 \mathrm{mM}$ PDCA, $33 \mathrm{mM}$ $\mathrm{KOH}$, and $37 \mathrm{mM} \mathrm{HCOOH}$ adjusted to $\mathrm{pH} 4$; postcolumn reagent: $100 \mathrm{mM} \mathrm{Na} \mathrm{CO}_{3}$ and $0.05 \mathrm{mM}$ luminol adjusted to pH 11.5 with $\mathrm{NaOH}$, and $600 \mathrm{mM} \mathrm{H}_{2} \mathrm{O}_{2}$ ). In Fig. 5a, where no $\mathrm{KCl}$ was added, the elution time is long (about $19 \mathrm{~min}$ ) and the peak shape of $\mathrm{Fe}$ (II) is much broader (1.4 min) as compared to Fig. 5c, where the elution time is only $c a .6 \mathrm{~min}$ and the peak width is $0.5 \mathrm{~min}$ with the addition of $80 \mathrm{mM} \mathrm{KCl}$. Thus, the presence of a soluble salt affects the retention factor as well as the separation factor of the analytes $\left(\mathrm{Fe}[\mathrm{PCDA}]_{2^{2-}}\right.$ and $\left.\mathrm{Fe}[\mathrm{PCDA}]_{2}^{-}\right),{ }^{29}$ and in this case much more so for the more negatively charged $\mathrm{Fe}[\mathrm{PCDA}]_{2}{ }^{2-}$. This is so because a higher salt concentration results in a greater electrostatic interaction between the anion-exchange sites on the stationary phase (SP) and the chloride ions, hence resulting in a smaller electrostatic interaction between the SP and the analytes. The net result is a smaller partition ratio in the SP, and the analytes spend more time in the mobile phase, thus exhibiting a shorter retention time and less peak broadening. However, a too high $\mathrm{KCl}$ concentration results in a too small separation factor (Figs. 5d and $5 \mathrm{e}, 100 \mathrm{mM}$ and $120 \mathrm{mM} \mathrm{KCl}$ ), and the peaks start to overlap. Therefore, $80 \mathrm{mM} \mathrm{KCl}$ is selected as the optimum salt concentration. From Fig. 5, one also observes that the migration of $\mathrm{Fe}(\mathrm{III})$ increases with an increase in the chloride concentration at a much smaller rate than $\mathrm{Fe}(\mathrm{II})$. This is so because the electrostatic interaction between the SP and the Fe(III)-PDCA complex is inherently weaker to begin with, and hence is less affected by a decrease in the electrostatic interaction.

\section{Optimizing the postcolumn reagent condition}

With the eluent conditions optimized and fixed at $10 \mathrm{mM}$ PDCA, $33 \mathrm{mM} \mathrm{KOH}$, and $37 \mathrm{mM} \mathrm{HCOOH}$ adjusted to $\mathrm{pH} 4$, optimization of the postcolumn reagent was then performed by studying the effects of the buffer solution, luminol concentration, and oxidant concentration.

Effect of anions of the buffer solution. Chemiluminescence systems are complex and not well understood. Luminol luminescence is the most studied and best understood among others discovered. Even thuogh luminol can behave differently in different environments, its behavior has not been fully explained. It has been reported that the presence of carbonate ions enhances the signal-to-noise ratio, ${ }^{30}$ and so its effect is compared to borate ions used as a buffer in the postcolumn reagent. The result in Fig. 6a shows that carbonate ions indeed enhance the peak areas by more than 10 times, as opposed to borate ions, and thus sodium carbonate was chosen as the buffer solution. The effect of the carbonate concentration in the luminol solution on the luminescence is shown in Fig. $6 \mathrm{~b}$ with the postcolumn reagent containing $0.05 \mathrm{mM}$ luminol adjusted to pH 11.5 with $\mathrm{NaOH}$ and $600 \mathrm{mM} \mathrm{H}_{2} \mathrm{O}_{2}$. The intensity peaks when the carbonate concentration is $100 \mathrm{mM}$, and hence this concentration was selected as the optimized condition.

Effect of the luminol concentration. Figure $6 \mathrm{c}$ shows the effect of the luminol concentration on the signal intensity. Under the

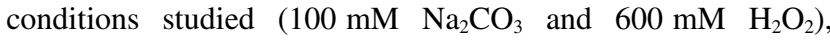
the intensity demonstrates an almost linear relationship to the luminol concentration. Owing to the sensitive nature of the luminescence detector, the detector saturates when the luminol concentration reaches $0.1 \mathrm{mM}$. Hence, a luminol concentration of $0.05 \mathrm{mM}$ was chosen as the optimized condition.

Effect of an oxidizing agent. An oxidizing agent is required for the luminol chemiluminescence reaction to occur. The most 

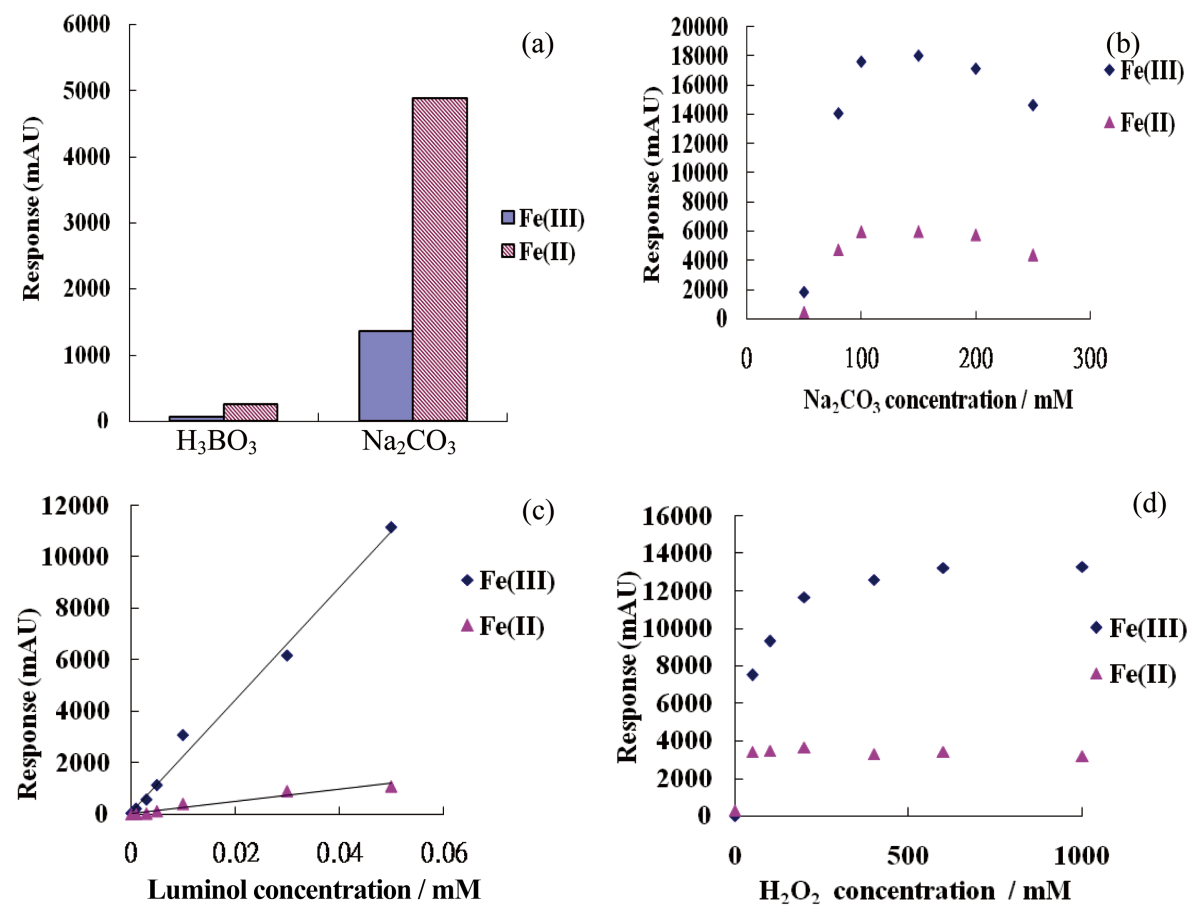

(c)

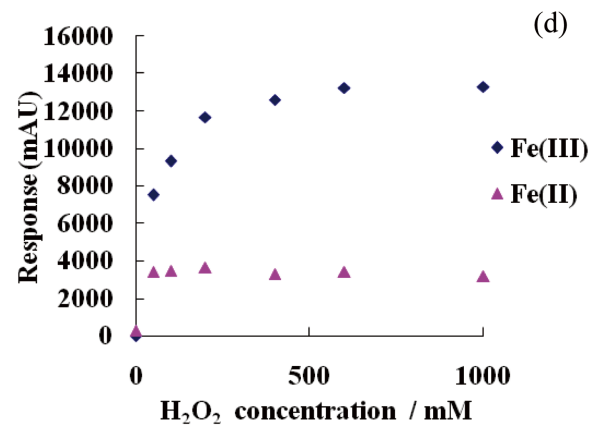

Fig. 6 (a) Effect of the presence of borate and carbonate ions in the luminol solution on the luminescence, (b) effect of the carbonate concentration in the luminol solution on the luminescence; both (a) and (b) at $0.05 \mathrm{mM}$ luminol (pH 11.5) and $600 \mathrm{mM} \mathrm{H}_{2} \mathrm{O}_{2}$, (c) effect of luminol concentration on the signal intensity at $100 \mathrm{mM} \mathrm{Na}_{2} \mathrm{CO}_{3}$ and $600 \mathrm{mM} \mathrm{H}_{2} \mathrm{O}_{2}$, and (d) effect of the $\mathrm{H}_{2} \mathrm{O}_{2}$ concentration on the signal intensity at $100 \mathrm{mM} \mathrm{Na}_{2} \mathrm{CO}_{3}$ and $0.05 \mathrm{mM}$ luminol $(\mathrm{pH} 11.5)$. The eluent contained $33 \mathrm{mM} \mathrm{KOH}, 37 \mathrm{mM} \mathrm{HCOOH}$, and $80 \mathrm{mM} \mathrm{KCl}$.

common oxidant used in this reaction is hydrogen peroxide. Figure $6 \mathrm{~d}$ shows the effect of the concentration of hydrogen peroxide on the luminescence intensity (postcolumn reagent: $100 \mathrm{mM} \mathrm{Na} \mathrm{CO}_{3}$ and $0.05 \mathrm{mM}$ luminol adjusted to $\mathrm{pH} 11.5$ with $\mathrm{NaOH}$ ). Without hydrogen peroxide added to the system, $\mathrm{Fe}$ (III) cannot be detected. However, a minute signal of Fe(II) could be detected, and it is postulated that this may be due to the slight amount of dissolved oxygen in the water, since it has been reported that the luminescence with $\mathrm{Fe}(\mathrm{II})$ can occur with reactive oxygen species other than hydrogen peroxide. ${ }^{14}$ In addition, the constant luminosity with $\mathrm{Fe}(\mathrm{II})$ from the addition of 50 to $1000 \mathrm{mM}$ hydrogen peroxide in the present study also suggests that hydrogen peroxide is not the oxidizing agent responsible for the reaction. Since hydrogen peroxide decomposes readily in water to form molecular oxygen, we postulate that molecular oxygen is the favored oxidant in this case. On the other hand, the signal intensity of the Fe(III) luminosity is dependent on the presence of hydrogen peroxide, and increases logarithmically with the addition of hydrogen peroxide, and peaks at around $600 \mathrm{mM}$. Consequently, $600 \mathrm{mM}$ has been determined as the optimized condition.

\section{Summary of optimized conditions}

From the above experiments, the optimized conditions for the eluent are determined as $10 \mathrm{mM}$ PDCA with $80 \mathrm{mM} \mathrm{KCl}$ fixed at $\mathrm{pH} \mathrm{4}$, whereas those for postcolumn reagent are $100 \mathrm{mM}$ sodium carbonate and $0.05 \mathrm{mM}$ luminol fixed at $\mathrm{pH} 11.5$, and $600 \mathrm{mM}$ hydrogen peroxide.

\section{Interference study}

Interference from some common metal cations, such as $\mathrm{Cd}$, $\mathrm{Ca}, \mathrm{Cr}, \mathrm{Cu}, \mathrm{Mg}, \mathrm{Ni}, \mathrm{Pb}$, and $\mathrm{Zn}$, was studied by the addition of

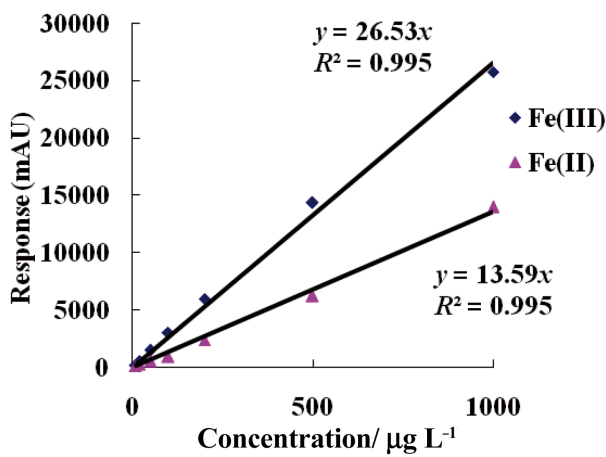

Fig. 7 Calibration curve and linear dynamic range of ferrous and ferric ions performed in the simultaneous detection mode.

$1000 \mu \mathrm{g} \mathrm{L}^{-1}$ each of these metal ions to a sample fortified with $300 \mu \mathrm{g} \mathrm{L}^{-1}$ each of $\mathrm{Fe}(\mathrm{II})$ and $\mathrm{Fe}(\mathrm{III})$. The result showed no interferences from these metal ions on both analytes.

\section{Limits of detection and linear dynamic range}

The liner dynamic range of this method was studied by establishing calibration from $0-1000 \mu \mathrm{g} \mathrm{L}^{-1}$; both $\mathrm{Fe}$ (II) and $\mathrm{Fe}$ (III) showed linear calibration in this range with $R^{2}>0.995$ (Fig. 7). The method detection limits (MDLs) of Fe(II) and $\mathrm{Fe}(\mathrm{III})$ were calculated by analyzing seven samples fortified with $100 \mu \mathrm{L}$ of low ferrous and ferric ion concentrations in the simultaneous detection mode and were computed as $7 \mu \mathrm{g} \mathrm{L}^{-1}$ (13 pmol on column) and $3 \mu \mathrm{g} \mathrm{L}^{-1}$ (5.4 pmol on column), respectively. Comparing these results to those reported by 
Table 1 Analytical results of ferrous and ferric ions in real samples and the corresponding spike recoveries

\begin{tabular}{|c|c|c|c|c|c|c|c|c|c|c|}
\hline \multirow{2}{*}{ Real sample } & \multicolumn{2}{|c|}{$\begin{array}{l}\text { Sample concentration/ } \\
\qquad \mu \mathrm{g} \mathrm{L}^{-1}\end{array}$} & \multicolumn{2}{|c|}{$\begin{array}{l}\text { Spiked concentration/ } \\
\qquad \mu \mathrm{g} \mathrm{L}^{-1}\end{array}$} & \multicolumn{2}{|c|}{$\begin{array}{l}\text { Measured concentration/ } \\
\qquad \mu \mathrm{g} \mathrm{L}^{-1}\end{array}$} & \multicolumn{2}{|c|}{$\begin{array}{l}\text { RSD of triplicate } \\
\text { measurement, } \%\end{array}$} & \multicolumn{2}{|c|}{$\begin{array}{c}\text { Spike recovery, } \\
\%\end{array}$} \\
\hline & $\mathrm{Fe}(\mathrm{II})$ & $\mathrm{Fe}(\mathrm{III})$ & $\mathrm{Fe}(\mathrm{II})$ & $\mathrm{Fe}(\mathrm{III})$ & $\mathrm{Fe}(\mathrm{II})$ & $\mathrm{Fe}(\mathrm{III})$ & $\mathrm{Fe}(\mathrm{II})$ & $\mathrm{Fe}(\mathrm{III})$ & $\mathrm{Fe}(\mathrm{II})$ & $\mathrm{Fe}(\mathrm{III})$ \\
\hline Effluent & ND & 21 & 250 & 300 & 239 & 305 & 4.8 & 0.9 & 96 & 95 \\
\hline Tap water & ND & ND & 250 & 300 & 238 & 306 & 4.0 & 2.7 & 95 & 102 \\
\hline Drinking water & ND & ND & 250 & 300 & 244 & 299 & 1.7 & 3.8 & 98 & 100 \\
\hline Seawater & ND & ND & 250 & 300 & 247 & 291 & 0.8 & 4.6 & 99 & 97 \\
\hline
\end{tabular}

ND $=$ Not detected

Cardellicchio et al. (2.2 and $0.3 \mu \mathrm{g} \mathrm{\textrm {L } ^ { - 1 }}$ for $\mathrm{Fe}(\mathrm{II})$ and $\mathrm{Fe}(\mathrm{III})$, respectively, with $750 \mu \mathrm{L}$ injection volume, ${ }^{20}$ which translates to 30 pmol of $\mathrm{Fe}(\mathrm{II})$ and $4.0 \mathrm{pmol} \mathrm{Fe}(\mathrm{III})$ on column), the present method is 2.3-times more sensitive for Fe(II) and 1.4-times less sensitive for $\mathrm{Fe}(\mathrm{III})$.

\section{Analysis of real samples}

The analytical method was evaluated by the analysis of real samples and their corresponding matrix spike recoveries. Four water samples (one from bottled drinking water, one from tap water, one from seawater, and one from an effluent by the university) were collected. Sample preparation was done by just simple filtration through $0.45 \mu \mathrm{m}$ nylon filters. The analytical results are given in Table 1. Out of the four samples, only the effluent sample contained $21 \mu \mathrm{g} \mathrm{L}^{-1}$ of $\mathrm{Fe}(\mathrm{III})$. All four samples contained no $\mathrm{Fe}(\mathrm{II})$. The spike recoveries on these four samples were between 95 to $99 \%$ for $\mathrm{Fe}(\mathrm{II})$ and 95 to $102 \%$ for $\mathrm{Fe}(\mathrm{III})$, with RSDs of triplicate measurements range from 0.8 to $4.8 \%$. These results indicate that this method is a highly selective and sensitive technique for the low-level detection and speciation of iron.

\section{Conclusion}

This study explores the speciation of a low-level iron concentration by ion-chromatography (IC) equipped with luminol chemiluminescence detection. With the optimized conditions, the linear calibration range is found to be roughly three-orders of magnitude, and the detection limit is $7 \mu \mathrm{g} \mathrm{L}^{-1}$ for $\mathrm{Fe}(\mathrm{II})$ and $3 \mu \mathrm{g} \mathrm{L}^{-1}$ for $\mathrm{Fe}(\mathrm{III})$ with a $100-\mu \mathrm{L}$ injection volume. This method is relatively free from interference from common metal cations, such as $\mathrm{Cd}, \mathrm{Ca}, \mathrm{Cr}, \mathrm{Cu}, \mathrm{Mg}, \mathrm{Ni}, \mathrm{Pb}$, and $\mathrm{Zn}$. Matrix spike recoveries from four real samples showed satisfactory results of 95 to $99 \%$ for Fe(II) and 95 to $102 \%$ for $\mathrm{Fe}(\mathrm{III})$. This method requires very little sample preparation, short analysis time, and inexpensive instrumentation to achieve low-level detection and the speciation of iron in aqueous samples, and offers an attractive alternative to situations that prohibit expensive instrumentation.

\section{Acknowledgements}

We thank the National Science Council of Taiwan for financial support under Grant NSC96-2113-M-033-009-MY2.

\section{References}

1. H. Bagheri, A. Gholami, and A. Najafi, Anal. Chim. Acta,
2000, 424, 233.

2. P. Mytides, S. Rozou, D. Benaki, and E. A. Vyza, Anal. Chim. Acta, 2006, 566, 122.

3. A. Babaei, M. Babazadeh, and E. Shams, Electroanalysis, 2007, 19, 978.

4. B. Wang, X. L. Guan, Y. Hu, and Z. X. Su, J. Polym. Res., 2008, 15, 427.

5. H. Q. Luo, L. N. Li, and N. B. Li, Anal. Sci., 2006, 22, 621.

6. J. F. Staden and M. C. Matoetoe, Anal. Chim. Acta, 1998, $376,325$.

7. K. Saitoh, T. Hasebe, N. Teshima, M. Kurihara, and T. Kawashima, Anal. Chim. Acta, 1998, 376, 247.

8. K. Sutton, R. M. C. Sutton, and J. A. Caruso, J. Chromatogr, A, 1997, 789, 85.

9. L. Wang, P. Yang, Y. Li, and C. Zhu, Talanta, 2006, 70, 219.

10. B. F. Liu, M. Ozaki, Y. Utsumi, T. Hattori, and S. Terabe, Anal. Chem., 2003, 75, 36.

11. H. Kubo and A. Toriba, Anal. Chim. Acta, 1997, 353, 345.

12. D. Badocco, P. Pastore, G. Favaro, and C. Macc, Talanta, 2007, 72, 249.

13. Y. Zhou and G. Zhu, Talanta, 1997, 44, 2041.

14. A. L. Rose and T. D. Waite, Anal. Chem., 2001, 73, 5909.

15. C. Lu, J. M. Lin, C. W. Huie, and M. Yamada, Anal. Sci., 2003, 19, 557.

16. S. Baj and T. Krawczyk, Anal. Chim. Acta, 2007, 585, 147.

17. M. Yaqoob, A. Nabi, and P. J. Worsfold, Anal. Chim. Acta, 2004, 510, 213.

18. X. Ding and S. Mou, J. Chromatogr., A, 2001, 920, 101.

19. Dionex, Application Note 10.

20. N. Cardellicchio, S. Cavalli, P. Ragone, and J. M. Riviello, J. Chromatogr., A, 1999, 847, 251.

21. Y. Kanai, Analyst, 1990, 115, 809.

22. K. Aslan and C. D. Geddes, Chem. Soc. Rev., 2009, 38, 2556.

23. X. J. Ding, S. F. Mou, K. N. Liu, A. Siriraks, and J. Riviello, Anal. Chim. Acta, 2000, 407, 319.

24. M. R. B. Abas, I. A. Takruni, Z. Abdullah, and N. M. Tahir, Talanta, 2002, 58, 883.

25. J. Jernstrom, J. Lehto, and M. Betti, J. Radioanal. Nucl. Chem., 2007, 274, 95.

26. J. A. Dean, "Lange's Handbook of Chemistry", 11th ed., 1973, Mcgraw-Hill, NY.

27. D. E. Bause and H. H. Patterson, Anal. Chem., 1979, 51, 2288.

28. C. A. Chang and H. H. Patters, Anal. Chem., 1980, 52, 653.

29. Z. L. Chen and R. Naidu, J. Chromatogr., A, 2004, 1023, 151.

30. C. Xiao, D. A. Palmer, D. J. Wesolowski, S. B. Lovitz, and D. W. King, Anal. Chem., 2002, 74, 2210. 